\title{
Aggregations of African Black Oystercatchers in remote coastal areas of the Northern Cape Province, South Africa
}

\author{
Author(s): \\ Geldenhuys L
}

\author{
Journal editor: \\ Pete Laver \\ Manuscript editor: \\ Les G Underhill
}

Received: March 3, 2018; Accepted: September 7, 2018; Published: September 07, 2018

Citation: Geldenhuys L. 2018. Aggregations of African Black Oystercatchers in remote coastal areas of the Northern Cape Province, South Africa. Biodiversity Observations 9.8:1-5

Journal: https://journals.uct.ac.za/index.php/BO/

Manuscript: https://journals.uct.ac.za/index.php/BO/article/view/572

PDF: https://journals.uct.ac.za/index.php/BO/article/view/572/555

HTML: http:/ / thebdi.org/blog/2018/09/07/african-black-oystercatcher-aggregations
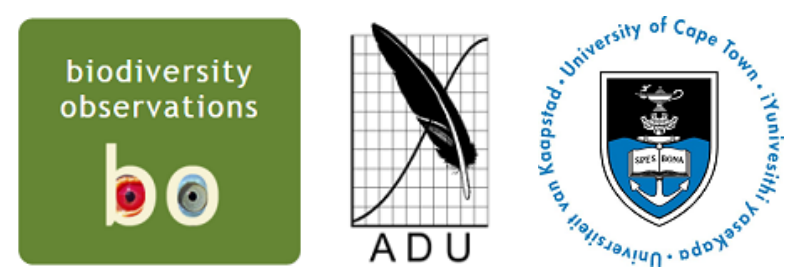

Biodiversity Observations is an open access electronic journal published by the Animal Demography Unit at the University of Cape Town, available at https://journals.uct.ac.za/index.php/BO/

The scope of Biodiversity Observations includes papers describing observations about biodiversity in general, including animals, plants, algae and fungi. This includes observations of behaviour, breeding and flowering patterns, distributions and range extensions, foraging, food, movement, measurements, habitat and colouration/plumage variations. Biotic interactions such as pollination, fruit dispersal, herbivory and predation fall within the scope, as well as the use of indigenous and exotic species by

humans. Observations of naturalised plants and animals will also be considered. Biodiversity Observations will also publish a variety of other interesting or relevant biodiversity material: reports of projects and conferences, annotated checklists for a site or region, specialist bibliographies, book reviews and any other appropriate material. Further details and guidelines to authors are on the journal website (https://journals.uct.ac.za/index.php/BO/). 


\title{
Aggregations of African Black Oystercatchers in remote coastal areas of the Northern Cape Province, South Africa
}

\section{Louise Geldenhuys}

X16, Springbok, 8240
Northern Cape Department of Environment and Nature Conservation, Private Bag

\begin{abstract}
Counts of African Black Oystercatchers along the Northern Cape Coastline, excluding the Namaqua National Park, were conducted during August and November of 2015, 2016 and 2017. An average of 387 oystercatchers were counted in this area. The area between Port Nolloth and Kleinsee accounted for $46 \%$ of oystercatchers counted, and this relatively undisturbed and remote area could be an important site for the conservation of oystercatchers in South Africa.
\end{abstract}

\section{Introduction}

The African Black Oystercatcher Haematopus moquini is endemic to southern Africa, and breeds in the narrow coastal zone and on the offshore islands from southern Namibia to southern KwaZulu-Natal, South Africa (Hockey et al. 2003, Underhill 2014). Adults are monogamous and territorial, and will stay in their territory for life, but pre-breeding juveniles migrate between 150 and $2000 \mathrm{~km}$ during the first few years of their lives, after which they return to find a territory close to where they hatched. African Black Oystercatchers feed during low tide, and aggregate at specific roost sites during high tides (Figure 1). During the breeding season breeding birds do not join these roosts, and the aggregations of birds at roosts consists of juveniles and immature non-breeding birds. These aggregations of non-breeding birds usually feed in the vicinity of the roost (Rao et al. 2014).

The sites of these roosts stay more or less constant over years, and the conservation of these sites is important for the long-term survival of the species (Rao et al. 2014). The locations of these roost sites have previously been identified through aerial surveys of the coastline between Elands Bay in South Africa and the Kunene River at the border of Namibia and Angola (Rao et al. 2014). This paper presents more recent (2015-2017) observations of aggregations of African Black Oystercatchers in the Northern Cape Province.

The conservation status of the African Black Oystercatcher has recently been changed from Near Threatened to Least Concern, following an increase in numbers (BirdLife International 2017). This change in threat status can be attributed to an overall increase in population size; this, in turn, is attributed to a massive increase in food resources as a result of the invasion of

Biodiversity Observations is an open access electronic journal published by the Animal Demography Unit at the University of Cape Town, available at https://journals.uct.ac.za/index.php/BO/. A permanent link for an online version of this manuscript can be found at https://journals.uct.ac.za/index.php/BO/article/view/572, which includes the PDF: https://journals.uct.ac.za/index.php/BO/article/view/572/555. An HTML version can be found at http:/ / thebdi.org/blog/2018/09/07/african-black-oystercatcher-aggregations.

Journal editor: Pete Laver; Manuscript editor: Les G Underhill; Corresponding author: louisegeldenhuys@ncpg.gov.za

Received: March 3, 2018; Accepted: September 7, 2018; Published: September 07, 2018

Recommended citation: Geldenhuys L. 2018. Aggregations of African Black Oystercatchers in remote coastal areas of the Northern Cape Province, South Africa. Biodiversity Observations 9.8:1-5

Manuscript subject: Distribution 
the coastline by the Mediterranean Mussel Mytilus galloprovincialis, the sensitive management of the offshore islands along the South African and Namibian coastlines, and the exclusion of off-road vehicles from the coastline of South Africa (Underhill 2014).

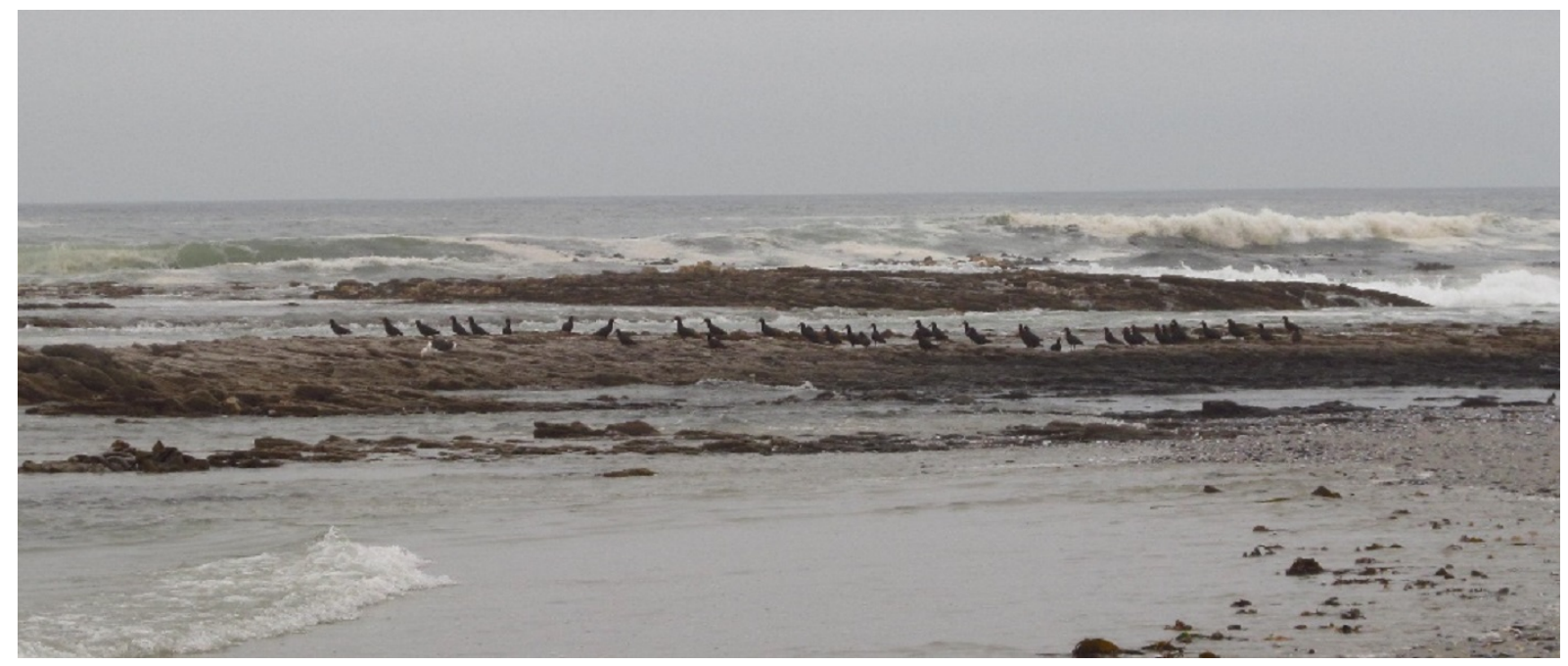

Figure 1: A group of 39 African Black Oystercatchers between Port Nolloth and Kleinsee.

\section{Northern Cape African Black Oystercatcher surveys: 2015 to 2017}

African Black Oystercatcher numbers and locations were recorded during the annual Northern Cape coastal audits. Counts were conducted from $4 \times 4$ vehicles traveling as close to the coastline as possible. Counts were done throughout the day, and not exclusively during high tide. The area surveyed was divided into a northern and southern section (Figures 2 and 3), and each section was surveyed twice (northern section 2015 and 2017, and southern section 2015 and 2016). The area of the Namaqua National Park was excluded from these surveys.

In the northern section (Orange River Mouth to Kleinsee), totals of 290 and 364 oystercatchers were counted in 2015 and 2017 respectively. In the southern section (Western Cape boundary to Kleinsee), totals of 80 and 39 oystercatchers were counted in 2015 and 2016, respectively.

For the entire Northern Cape coastline, excluding the Namaqua National Park, 370 oystercatchers were counted in the combined two sections in 2015, and 403 oystercatchers in the two sections in 2016 and 2017 combined. These totals are much greater than previously reported for oystercatchers between the Orange and Olifants Rivers as a total of 86 (1978-1980) and 79 (19972002) (Underhill 2014). It is not known if this difference is due to the differences in observation methods used, or if it is a reflection of an increase in oystercatcher numbers. It is more likely to be the latter; for example, on Robben Island, mean oystercatcher numbers increased from c. 120 in 2002 to 345 in 2012 to 516 in 2017 (Spiby 2012; Bukola Braimoh unpubl. observations).

\section{Aggregation areas}

In the northern section there were seven observations of groups of 10 or more oystercatchers in 2015, and 11 groups in 2017 (Figure 2). There were two groups of 10 or more oystercatchers in the southern section in 2015, and none in 2016 (Figure 3). Two of these aggregations occurred at the same place during both surveys (Figure 2), and these sites should be considered important for oystercatcher conservation. The area between Port Nolloth and Kleinsee appears to be an important area for aggregating oystercatchers, with an average of $46 \%$ of the total number of 


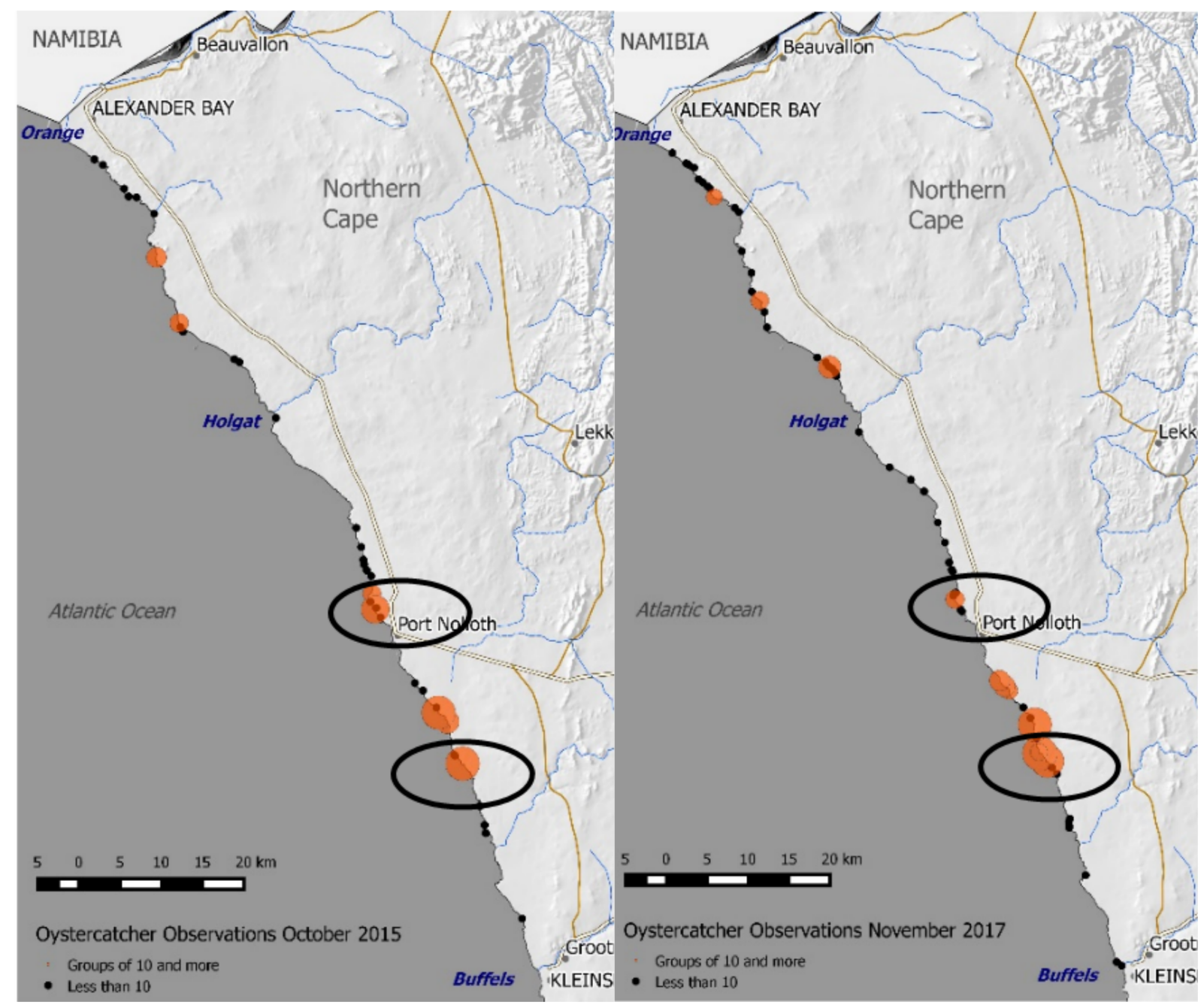

Figure 2: Oystercatcher counts in the northern section of the Northern Cape coastline in 2015 and 2017. Groups of ten or more are reflected by the orange circles (size correspond to group size). Large black circles indicates areas where groups were found in the same area in the different years. 


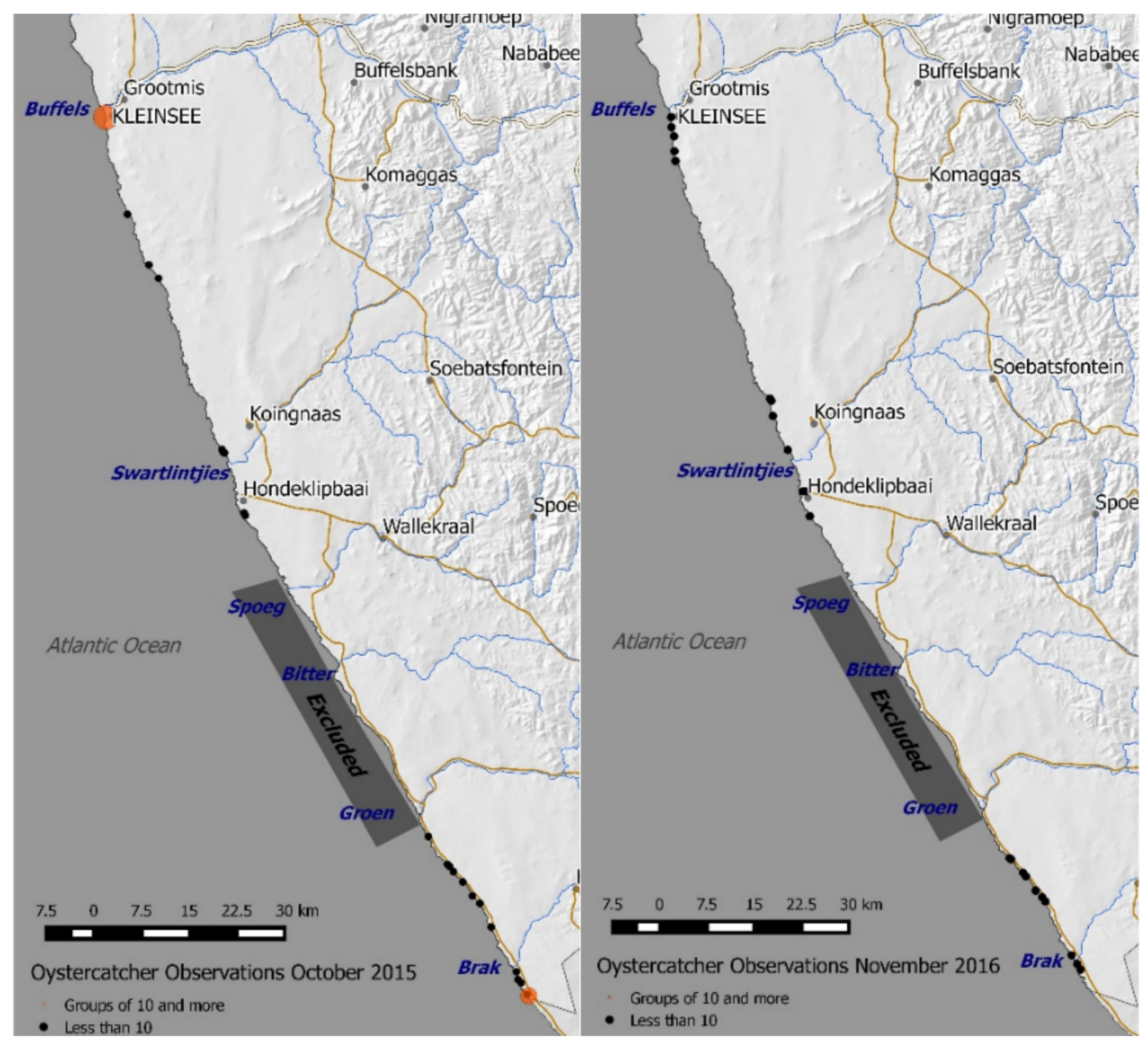

Figure 3: Oystercatcher counts in the southern section of the Northern Cape coastline in 2015 and 2016. Groups of ten or more are reflected by orange circles. There were no groups of ten or more observed in 2016. 
oystercatcers in the Northern Cape (excluding Namaqua National Park) found in this area. This area is also currently relatively undisturbed. While access is restricted by De Beers, no active mining is currently taking place, unlike the areas between Alexander Bay and Port Nolloth, and between Kleinsee and the Spoeg River Mouth, where intensive coastal diamond mining is taking place.

\section{Acknowledgements}

Klaas van Zyl, Enrico Oosthuysen, Marnus Smit, Conrad Geldenhuys, Johan Jonk, Thinus Jonker, Adeleen Cloete, Bronwen Cornelissen, and Wilna Oppel assisted with oystercatcher spotting and counting. Alexcor, De Beers, and West Coast Resources granted access into mining areas. The Northern Cape Department of Environment and Nature Conservation funded this survey.

\section{References}

BirdLife International 2017. Haematopus moquini. [The IUCN Red List of Threatened Species 2017]. Available from http:/ / www.iucnredlist.org/details/22693627/0, accessed on 25 January 2018.

Hockey PAR, Lesenberg A, Loewenthal D 2003. Dispersal and migration of juvenile African Black Oystercatchers Haematopus moquini. Ibis 145: E114-E123.

Rao AS, Hockey PAR, Montevecchi WA 2014. Coastal dispersal by pre-breeding African Black Oystercatchers Haematopus moquini. Marine Ornithology 42: 105-112.

Spiby J 2012. Trends in African Black Oystercatchers Haematopus moquini on Robben Island, South Africa: population size and nest characteristics. BSc(Hons) project, Department of Zoology, University of Cape Town.

Underhill LG 2014. Assessment of the conservation status of African Black Oystercatcher Haematopus moquini. International Water Studies 20:97-108. 